\title{
In vitro monitoring of nanogram levels of naproxen in human urine using flow injection chemiluminescence
}

\author{
Xianglei Cheng ${ }^{\text {a }}$, Lixia Zhao ${ }^{\text {a }}$, Meilin Liu ${ }^{\text {a }}$, Jin-Ming Lin ${ }^{\text {a }}$ b,* \\ ${ }^{a}$ State Key Laboratory of Environmental Chemistry and Ecotoxicology, Research Center for Eco-Environmental Sciences, \\ Chinese Academy of Sciences, Beijing 100085, China \\ ${ }^{\mathrm{b}}$ Department of Chemistry, Tsinghua University, Beijing 100084, China
}

Received 17 July 2005; received in revised form 21 October 2005; accepted 31 October 2005

Available online 20 December 2005

\begin{abstract}
Based on the synergic effect of the hydrophobicity of sodium dodecylbenzenesulfonate (SDBS) micelles and the incorporation of naproxen molecules, a simple, rapid and sensitive chemiluminescence (CL) method was described for the determination of naproxen in pharmaceuticals and urine. Under the optimum experimental conditions, the CL intensity was linear over the concentration of naproxen ranging from 1.0 to $700.0 \mathrm{ng} \mathrm{mL}^{-1}(r=0.9917)$ with a detection limit as low as $0.9 \mathrm{ng} \mathrm{mL}^{-1}(\mathrm{~S} / \mathrm{N}=3)$. The mechanism of CL was discussed in detail based on the spectrometry. The experimental results demonstrated that the excretive amounts of naproxen reached its maximum in $4.0 \mathrm{~h}$ after taking $200 \mathrm{mg}$ naproxen tablet; and the naproxen excretive ratio during $8.0 \mathrm{~h}$ was $5.46 \%$ in the body of volunteers.
\end{abstract}

(C) 2005 Elsevier B.V. All rights reserved.

Keywords: Chemiluminescence; Naproxen; Urine; Flow injection analysis

\section{Introduction}

Naproxen $(S)-(+)-6$-methoxy- $\alpha$-methyl-2-naphthalene acetic acid, is a non-steroidal anti-inflammatory drug widely used as mild to moderate pain relief and in the treatment of osteoand rheumatoid arthritis [1]. Its chronic or acute administration shows toxic manifestations generally characteristic of non-steriodal anti-inflammatory drugs, such as gastrointestinal erosion, bleeding and pathologic changes in the real cortex and papillae. Moreover, they are associated with other serious side effects, i.e. kidney failure, and with a number of minor side effects, such as nausea vomiting, diarrhea, constipation, decreased appetite, rash, dizziness, headache and drowsiness. Finally, they also interact with other drugs; in particular, they reduce the action of diuretics and antagonize the action of drugs used to treat hypertension.

In view of the above considerations, the development of a simple and reproducible method for the determination of naproxen in biological fluids could be very useful for toxicological and

\footnotetext{
* Corresponding author. Tel.: +86 10 62841953; fax: +86 1062841953 .

E-mail addresses: jmlin@mail.rcees.ac.cn, jmlin@mail.tsinghua.edu.cn (J.-M. Lin)
}

pharmaceutical purposes. Several analytical methods have been reported in the scientific literatures for the determination of naproxen in pharmaceutical preparations and biological fluids including HPLC [2], spectrofluorimetry [3,4], capillary electrophoresis [5], phosphorimetry [6], differential pulse voltammetry [7] and capillary isotachophoresis [8]. However, for such application, the chromatographic methods involve more sophisticated instrumentation and higher cost of per analysis in addition to the complexity of their separation systems. Because of a narrow linear range and serious interference from metrics, spectrofluorometric determination was usually tedious in monitoring the excretive profile of biological fluids [9]. As far as roomtemperature phosphorescence, too large injection volume, temperature sensitivity and the hazards of manipulating compounds of high toxicity (as Tl(I) salts) are the main reasons of its limitation of use. Only one paper with chemiluminescence (CL) determination of naproxen was reported by Campiglio [10] based on the $\mathrm{CL}$ reaction with cerium (IV) in sulfuric acid medium. However, the CL method based on the reduction reaction of acidic cerium (IV) suffered from high interference from reducible substances such as cysteine and ascorbic acid [11], respectively, which were limited to the determination of analytes in pharmaceutical and biological samples. Moreover, the cerium-naproxen 
CL method mentioned above was in sulfuric acid medium and naproxen was less soluble in aqueous solution when $\mathrm{pH}$ value was low (<4.8), which resulted in poor sensitivity $\left(15 \mathrm{ng} \mathrm{mL}^{-1}\right)$ and narrow dynamic ranges (100-1000 $\mathrm{ng} \mathrm{mL}^{-1}$ ). In addition, in many cases, the rates of the CL reaction in an aqueous system are very fast, bad solubility would result in imprecise measurements.

Some approaches have been reported to overcome these difficulties. Micelles have been demonstrated to influence the chemistry and photophysics of molecules by altering the microenvironment in which the molecules reside. Micelles can change microviscosity, local $\mathrm{pH}$, polarity, reaction pathway or rate, etc. Sodium dodecylbenzenesulfonate (SDBS), as an anionic surfactant, having a unique structure in the hydrophobic group including a benzyl and a dodecyl group, was applied to the present method and the function of it was made clear in detail.

To the best of our knowledge, it was the first paper that reported the excretive profile of naproxen using CL method. Wang and Song [12] reported a rapid and sensitive CL method for the determination of trace puerarin in human urine with a wide linear range and a detection limit as low as $0.1 \mathrm{ng} \mathrm{mL}^{-1}$ based on the CL reaction of luminol and $\mathrm{KIO}_{4}$ in alkaline condition. Although luminol was a good and useful CL reagent, from the results of our usual experiments it could also be easily absorbed on the tubing walls and difficult being cleaned.

In this paper, a simple, rapid and sensitive method was proposed with wide dynamic ranges. It was found that naproxen could dramatically enhance the CL intensity from sulfite in acidic medium. The enhancement of CL intensity was proportional to the concentration of naproxen ranging from $1.0 \mathrm{ng} \mathrm{mL}^{-1}$ to $0.7 \mu \mathrm{g} \mathrm{mL}^{-1}$ with a relative standard deviation of $1.46 \%$ for 11 repeated determination of $10 \mathrm{ng} \mathrm{mL}^{-1}$ naproxen and the detection limit was $0.9 \mathrm{ng} \mathrm{mL}^{-1}$. The proposed method could be applied successfully in the determination of naproxen in human urine samples. The results showed that the excretive amounts of naproxen reached its maximum after taking the tablets $4.0 \mathrm{~h}$, with a total excretive ratio of $5.46 \%$ in $8.0 \mathrm{~h}$.

\section{Experimental}

\subsection{Reagents}

Chemicals of analytical grade were used as received. Ultrapure water was obtained from a compact ultrapure water system $(18.3 \mathrm{M} \Omega \mathrm{cm}$, Barnstead, IA, USA). SDBS was purchased from Fisher Scientific Ltd. (Hong Kong). Standard solution of SDBS were prepared by further dilution of its stock solution $\left(0.1 \mathrm{~mol} \mathrm{~L}^{-1}\right)$. Naproxen was from Sigma (Sigma-Aldrich Co., USA). A stock solution of $1.0 \times 10^{-2} \mathrm{~mol} \mathrm{~L}^{-1}$ sulfite was prepared daily by dissolving $0.1260 \mathrm{~g}$ sodium sulfite anhydrous (Beijing Yili Fine Chemical Ltd., Beijing, China) in $100.0 \mathrm{~mL}$ water. Hydrochloric acid was from Beijing Chemical Industry Plant (Beijing, China).

\subsection{Apparatus and procedure}

A batch style BPCL luminescence analyzer (Institute of Biophysics, Chinese Academy of Science, Beijing, China) was used

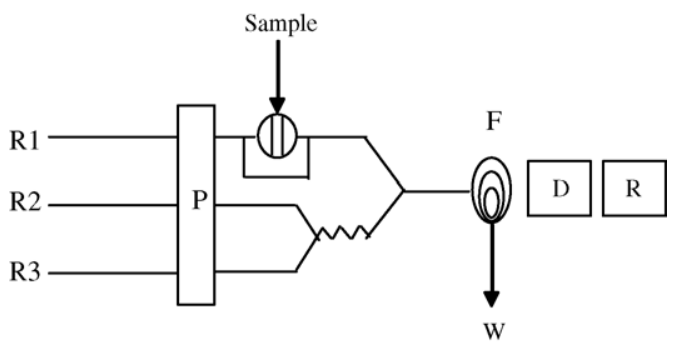

Fig. 1. Schematic diagram of the flow injection CL system for the determination of naproxen: R1: $0.060 \mathrm{~mol} \mathrm{~L}^{-1}$ hydrochloric acid solution; R2: $5.0 \times 10^{-4} \mathrm{~mol} \mathrm{~L}^{-1}$ SDBS; R3: $1.0 \times 10^{-5} \mathrm{~mol} \mathrm{~L}^{-1}$ sulfite; D: detector; F: flow cell; P: peristaltic pump; R: computer; $\mathrm{W}$ : waste; the flow rate: $2.5 \mathrm{~mL} \mathrm{~min}^{-1}$.

to obtain batch CL signals. A schematic diagram of the flow injection CL system in this work is shown in Fig. 1. Reagent solutions (R1-R3) were delivered by peristaltic pumps (P) through three flow-lines. The SDBS solution (R2) and the sulfite solution (R3) were mixed through a three-way piece, and then reacted in a mixing valve $(\mathrm{F})$ with the sample solution $(100 \mu \mathrm{L})$ which was injected into the carrier stream through the sample injection valve. The mixing coil was made by coiling a piece of glass tubing into a spiral disk shape and placed close to the photomultiplier tube. The CL emission was recorded with a flow injection CL analyzer (D, lumiflow LF-800, Microtec NITI-ON, Funabashi, Japan) controlled by a personal computer. PTFE tubing $(0.8 \mathrm{~mm}$ i.d.) was used to connect all components in the flow system. Calibration graphs were constructed by plotting the CL intensity (peak height) versus the concentration naproxen. The fluorescence and absorption spectra were monitored using a F2500 fluorescence spectrometer (Hitachi, Tokyo, Japan) and a Shimadzu UV-2401 UV-visible recording spectrophotometer (Shimadzu, Kyoto, Japan), respectively. The spectrofluorimeter was also adapted for the measurement of CL spectra.

The naproxen tablets were purchased from the local market. Twelve tablets were ground into fine powder and mixed. A sample equivalent to approximately $100 \mathrm{mg}$ preparations was weighed accurately and dissolved with $0.10 \mathrm{~mol} \mathrm{~L}^{-1} \mathrm{NaOH}$ solution and filtered. Then the solution was dissolved to $500 \mathrm{~mL}$ with water and diluted appropriately when determinated. Urine samples were collected from volunteers and a $1 \mathrm{~mL}$ aliquot of sample was mixed with $0.5 \mathrm{~mL}$ of acetonitrile and centrifuged for $5 \mathrm{~min}$ at $3000 \mathrm{~g}$. Then the supernatant was fetched and the rest acetonitrile was blow-dried under a gentle stream of nitrogen gas. Finally, the prepared sample was diluted at $5 \times 10^{3}$ with distilled water and sometimes supplemented with naproxen to test the recovery of the method.

\section{Results and discussion}

\subsection{The batch studies of $C L$}

The CL profiles in the batch method for the mixtures of naproxen, $\mathrm{SO}_{3}{ }^{2-}$, SDBS and $\mathrm{HCl}$ solution are shown in Fig. 2. The mixing of $\mathrm{SO}_{3}{ }^{2-}$ with SDBS in acidic solution gave weak CL emission (Fig. 2b), which was enhanced by adding a low concentration of naproxen solution. As shown in Fig. 2c, adding 


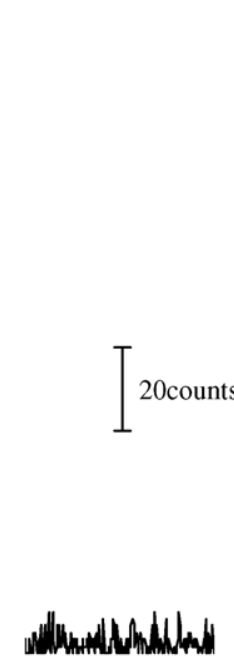

(a)

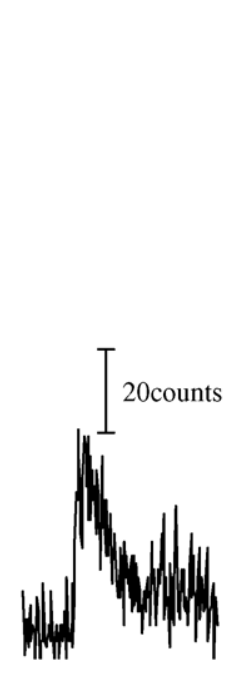

(b)

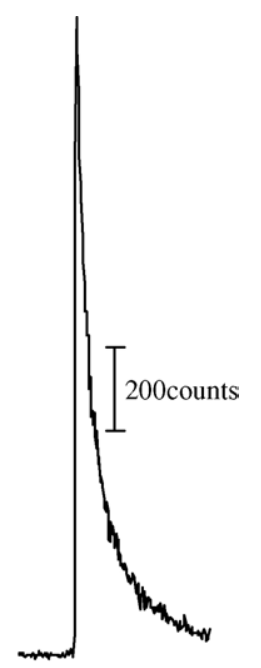

(c)
Fig. 2. Batch CL intensity-time profile. (a) Fifty microliters $\mathrm{HCl}+100 \mu \mathrm{L}$ sulfite; (b) $50 \mu \mathrm{L} \mathrm{HCl}+50 \mu \mathrm{L}$ SDBS $+100 \mu \mathrm{L}$ sulfite; (c) $50 \mu \mathrm{L} \mathrm{HCl}+50 \mu \mathrm{L}$ SDBS $+50 \mu \mathrm{L}$ naproxen $+100 \mu \mathrm{L}$ sulfite; [hydrochloric acid] $=0.060 \mathrm{~mol} \mathrm{~L}^{-1}$; $\left[\mathrm{SO}_{3}{ }^{2-}\right]=1.0 \times 10^{-5} \mathrm{~mol} \mathrm{~L}^{-1} ; \quad[\mathrm{SDBS}]=5.0 \times 10^{-4} \mathrm{~mol} \mathrm{~L}^{-1} ; \quad$ [naproxen] = $1.0 \times 10^{-6} \mathrm{~mol} \mathrm{~L}^{-1}$.

$100 \mu \mathrm{L}$ of $1.0 \times 10^{-5} \mathrm{~mol} \mathrm{~L}^{-1}$ sulfite solution into $50 \mu \mathrm{L}$ of naproxen in acidic solution and SDBS, a strong CL emission was recorded. The CL signal reaches a maximum within $0.4 \mathrm{~s}$ and then decreases relatively slowly. However, without SDBS no CL was observed (Fig. 2a).

\subsection{Effect of sulfite on the CL intensity}

The results of experiments showed that sulfite was the essential factor which dramatically influenced the CL signals of the present system. Then, on the basis of the primary experiments, the concentration of sulfite contributing to the CL signals was studied ranging from $1.0 \times 10^{-6}$ to $3.0 \times 10^{-5} \mathrm{~mol} \mathrm{~L}^{-1}$ in detail. Examination of Fig. 3 suggested that the relative CL intensity increased depending on the tendency of the sulfite when the concentration of sulfite was below $1.0 \times 10^{-5} \mathrm{~mol} \mathrm{~L}^{-1}$. Moreover, the $\mathrm{S} / \mathrm{N}$ ratio decreased when the concentration of sulfite con-

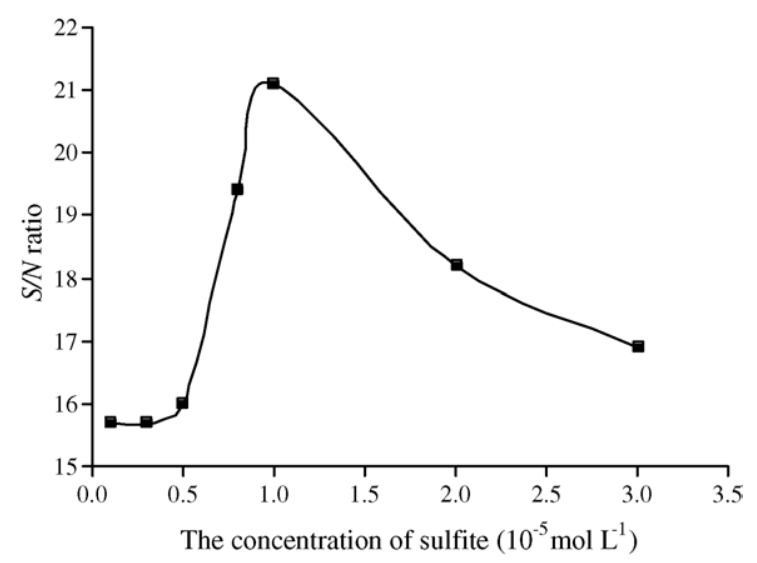

Fig. 3. The effect of sulfite concentration. [Hydrochloric acid] $=10 \mathrm{mmol} \mathrm{L}^{-1}$; $[\mathrm{SDBS}]=1 \times 10^{-3} \mathrm{~mol} \mathrm{~L}^{-1} ;$ [naproxen $]=1 \times 10^{-6} \mathrm{~mol} \mathrm{~L}^{-1}$.
Table 1

Effect of different surfactants by batch CL method

\begin{tabular}{llc}
\hline Surfactants & $\begin{array}{l}\mathrm{CMC} \\
\left(\mathrm{mol} \mathrm{L}^{-1}\right)\end{array}$ & $\begin{array}{c}\text { S/N } \\
\text { ratio }\end{array}$ \\
\hline None & & 1 \\
Sodium dodecylbenzenesulfonate (SDBS) & $2.9 \times 10^{-4}$ & 48 \\
Sodium dodecylsulfate (SDS) & $8.7 \times 10^{-3}$ & 2.5 \\
Tween 20 & $60^{\mathrm{a}}$ & 12.7 \\
Tween 85 & $13^{\mathrm{a}}$ & 1 \\
Cetylethyl-dimethylammonium bromide (CEDAB) & $6.0 \times 10^{-3}$ & 1 \\
Hexadecyltrimethylammonium bromide (CTAB) & $9.2 \times 10^{-4}$ & 1 \\
Hexadecyltrimethylammonium chloride (CTAC) & $1.3 \times 10^{-4}$ & 1 \\
Dodecyltrimethylammonium bromid (DTAB) & $1.6 \times 10^{-2}$ & 1 \\
\hline
\end{tabular}

a Concentration in $\mathrm{mg} \mathrm{L}^{-1}$.

tinued increasing. This could be contributed to the instability of noise when the concentration of sulfite and the product of emitter in the blank signal increased. The results illustrated that the maximum CL signal was found with sulfite at $1.0 \times 10^{-5} \mathrm{~mol} \mathrm{~L}^{-1}$.

\subsection{Effect of surfactant on the CL intensity}

Organized media could have a marked influence on the CL emission, almost no CL signals would be observed if there were no surfactants, which could be seen from the results of batch CL method. In an attempt to further improve the sensitivity of the CL signal, various surfactants, including cationic, anionic and non-ionic (surfactants), were tested in the reaction system. Each concentration of surfactant was prepared at higher concentration than the critical micelle concentration (CMC). As can be seen from Table 1, only the surfactants SDBS and Tween 20 had the effective enhancement on the CL signals. This was probably because different kinds of surfactants provided different microenvironments. The cationic surfactants increased the $\mathrm{pH}$ of micellar surface, which resulted in the decrease of CL intensity. On the other hand, SDBS attributed to its higher hydrophilicity than Tween 20 in aqueous solution. In the acidic condition, the naproxen molecules were the primary component of naproxen ( $\mathrm{p} K_{\mathrm{a}}$ of naproxen is 4.8) and appealed to the non-polar zone of micelles. Furthermore, the special chemical structure of SDBS with a benzyl group elicited the resolution of the naproxen molecules due to the naphthalene structure of themselves. Hence, SDBS was selected as sensitizer in this CL system.

The effect of SDBS concentration on the relative CL intensity was studied at different concentrations from $1 \times 10^{-4}$ to $5 \times 10^{-3} \mathrm{~mol} \mathrm{~L}^{-1}$. As illustrated in Fig. 4, with the concentration of SDBS increased in the range of $1 \times 10^{-4}$ to $5 \times 10^{-4} \mathrm{~mol} \mathrm{~L}^{-1}$, the $\mathrm{S} / \mathrm{N}$ ratio increased probably because of the formation of the micelles; while the maximum $\mathrm{S} / \mathrm{N}$ ratio was obtained when the SDBS concentration was $5 \times 10^{-4} \mathrm{~mol} \mathrm{~L}^{-1}$; and above the concentration of $5 \times 10^{-4} \mathrm{~mol} \mathrm{~L}^{-1}$, the $\mathrm{S} / \mathrm{N}$ ratio declined due to the noise of background CL increased rapidly. Then, $5 \times 10^{-4} \mathrm{~mol} \mathrm{~L}^{-1}$ of SDBS was chosen as optimum.

\subsection{Effect of hydrochloric acid}

Formic acid, acetic acid, hydrochloric acid, nitric acid, sulfuric acid and phosphoric acid were used, respectively, as the 


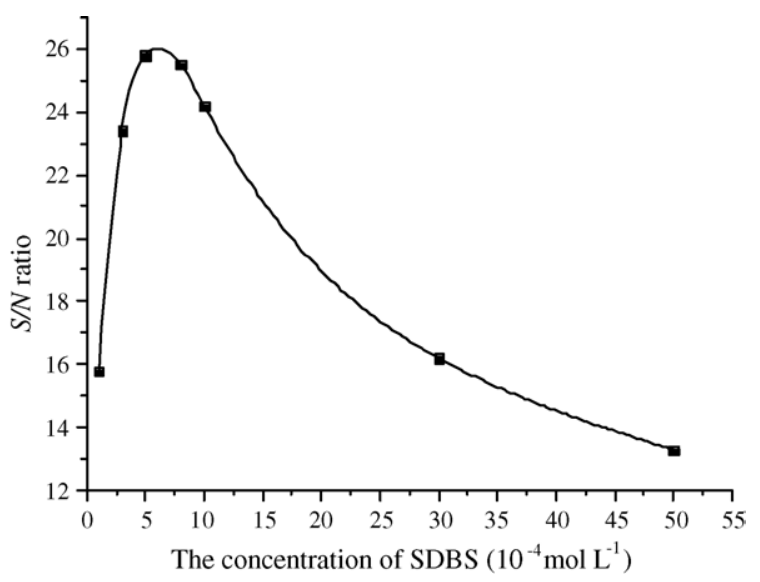

Fig. 4. The effect of SDBS on the CL intensity. $\left[\mathrm{SO}_{3}{ }^{2-}\right]=1 \times 10^{-5} \mathrm{~mol} \mathrm{~L}^{-1}$; [hydrochloric acid] $=10 \mathrm{mmol} \mathrm{L}^{-1}$; [naproxen] $=1 \times 10^{-6} \mathrm{~mol} \mathrm{~L}^{-1}$.

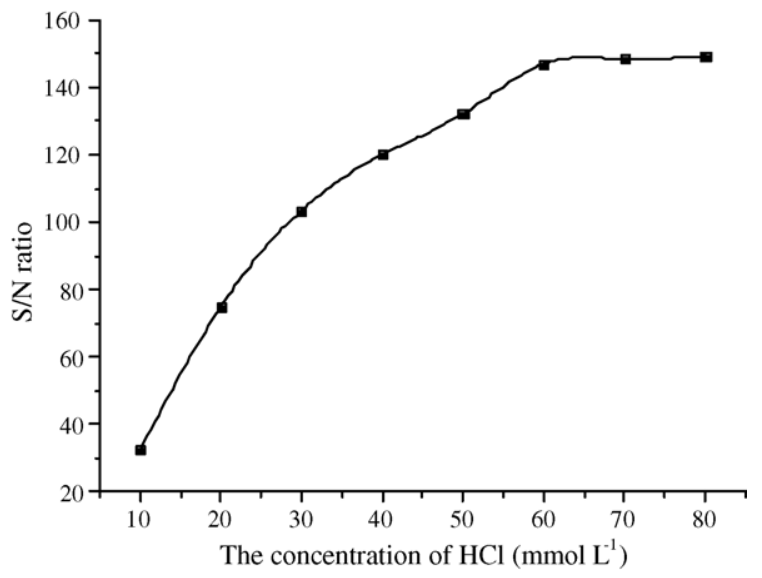

Fig. 5. The effect of hydrochloric acid on the $\mathrm{CL}$ intensity. $\left[\mathrm{SO}_{3}{ }^{2-}\right]=$ $1 \times 10^{-5} \mathrm{~mol} \mathrm{~L}^{-1} ; \quad[$ SDBS $]=5 \times 10^{-4} \mathrm{~mol} \mathrm{~L}^{-1} ; \quad$ [naproxen] $=1 \times 10^{-6} \mathrm{~mol}$ $\mathrm{L}^{-1}$.

reaction media to study their effect on the CL intensity. The results showed that the maximum CL signal was attained in hydrochloric acid (Table 2). The influence of different concentration of hydrochloric acid from 10 to $80 \mathrm{mmol} \mathrm{L}^{-1}$ was studied through the same flow manifold as demonstrated in Fig. 5. The present $\mathrm{CL}$ reaction occurred in acidic medium, so the $\mathrm{S} / \mathrm{N}$ ratio increased with the increasing of the concentration of hydrochlo-
Table 2

Effect of various inorganic acid by batch CL method

\begin{tabular}{lll}
\hline Inorganic acid & Concentration $\left(\mathrm{mmol} \mathrm{L}^{-1}\right)$ & S/N ratio \\
\hline $\mathrm{HCOOH}$ & 5 & 0 \\
$\mathrm{CH}_{3} \mathrm{COOH}$ & 5 & 0 \\
$\mathrm{HCl}$ & 5 & 175 \\
$\mathrm{HNO}_{3}$ & 5 & 130 \\
$\mathrm{H}_{2} \mathrm{SO}_{4}$ & 5 & 152 \\
$\mathrm{H}_{3} \mathrm{PO}_{4}$ & 5 & 140 \\
\hline
\end{tabular}

ric acid ranging from 10 to $60 \mathrm{mmol} \mathrm{L}^{-1}$. After that, the $\mathrm{S} / \mathrm{N}$ ratio grew nearly stable. This was due to two factors. One was that the background of the CL system increased as the concentration of $\mathrm{HCl}$ increased, the other was an excess of $\mathrm{HCl}$ was not in favor of the occurrence of the CL reaction. Thus, a concentration of $60 \mathrm{mmol} \mathrm{L}^{-1}$ was selected for this work.

\subsection{Effect of the flow rate}

In order to determine the optimum operating conditions of the flow system, the signal for $1.0 \times 10^{-6} \mathrm{~mol} \mathrm{~L}^{-1}$ naproxen was measured with respect to the flow rate of the reagent solutions. The flow rates of the CL system were investigated from 1.0 to $4.0 \mathrm{~mL} \mathrm{~min}^{-1}$. The flow rate of $2.5 \mathrm{~mL} \mathrm{~min}^{-1}$ was selected as an appropriate condition considering both good analytical precision and lower solution consumption.

\subsection{Performance of the proposed method}

Under the recommended conditions given above and following the procedure described in Section 2, the calibration graph was linear from $1.0 \mathrm{ng} \mathrm{mL}^{-1}$ to $0.7 \mu \mathrm{g} \mathrm{mL}^{-1}$. Fig. 6 showed the flow injection chemiluminescence signals for naproxen. The maximum peak height increased linearly with the increasing of naproxen concentration, as expressed by the equations $\Delta I=1.34 \times 10^{4} \lg C_{\text {naproxen }}+1.08 \times 10^{5}$. The detection limit is $0.9 \mathrm{ng} \mathrm{mL}^{-1}(\mathrm{~S} / \mathrm{N}=3)$, and the relative standard deviation was $1.46 \%$ for $10 \mathrm{ng} \mathrm{mL}^{-1}$ naproxen solution with eleven repeated measurements. As compared in Table 3, the present method has a wider linear range and lower detection limit than the previously reported.

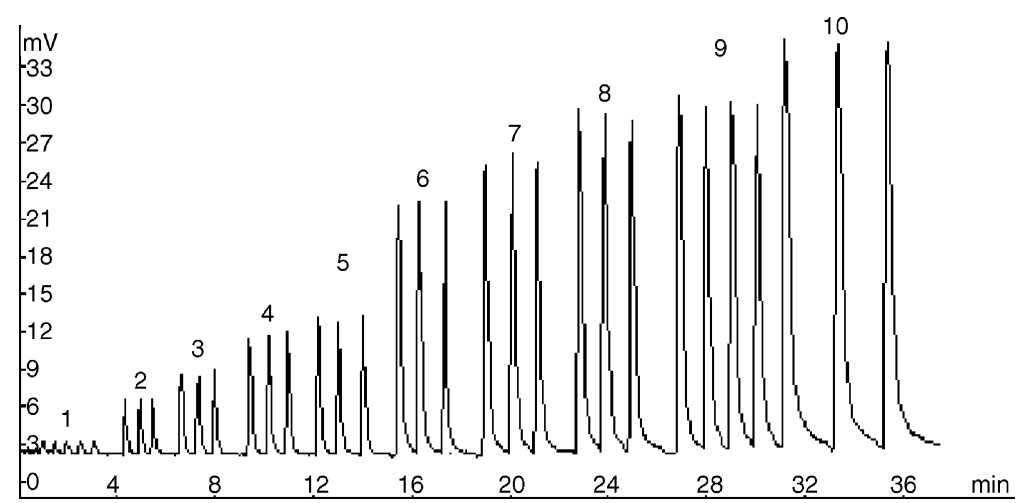

Fig. 6. Typical recorder response for the determination of naproxen $\left(\mathrm{ng} \mathrm{mL}^{-1}\right)$. (1) 1.0 ; (2) 3.0 ; (3) 5.0 ; (4) 7.0; (5) 10.0; (6) 50.0; (7) 70.0; (8) 100.0; (9) 500.0; (10) 700.0. 
Table 3

Comparison the present CL method for the determination of sulfite with other reported methods

\begin{tabular}{lccc}
\hline Method & $\begin{array}{l}\text { Detection } \\
\text { limit } \\
\left(\mathrm{ng} \mathrm{mL}^{-1}\right)\end{array}$ & $\begin{array}{l}\text { Dynamic } \\
\text { linear range } \\
\left(\mathrm{ng} \mathrm{mL}^{-1}\right)\end{array}$ & Reference \\
\hline This method & 0.9 & $1.0-700$ & \\
HPLC-UV & 50 & $2000-25000$ & {$[2]$} \\
Spectrofluorometry & 4 & $20-2000$ & {$[3]$} \\
RT phorsphorescence & 2.7 & $10-400$ & {$[6]$} \\
Pulse voltammetry & 240 & $1000-25000$ & {$[7]$} \\
Ce & $100-1000$ & {$[10]$} \\
\hline
\end{tabular}

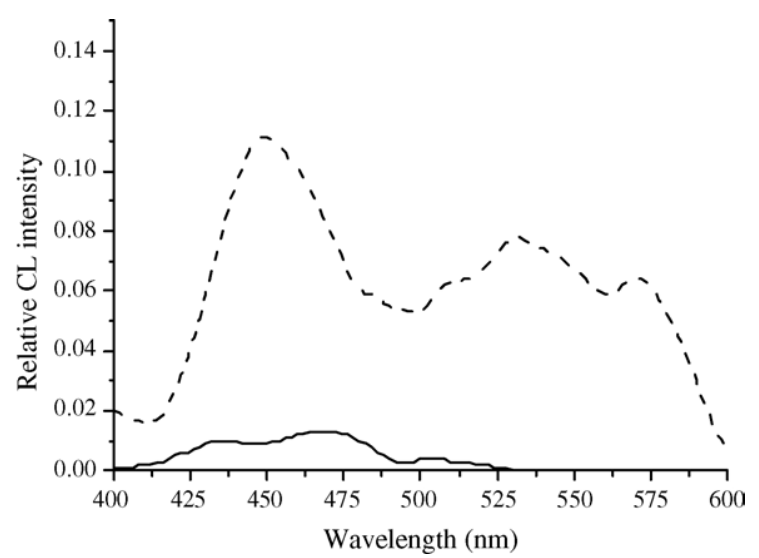

Fig. 7. The CL spectra of the present system. The CL spectra of $\mathrm{SO}_{3}{ }^{2-}+\mathrm{SDBS}+\mathrm{HCl}$ (solid) and $\mathrm{SO}_{3}{ }^{2-}+\mathrm{SDBS}+\mathrm{HCl}+$ naproxen (dash). $\left[\mathrm{SO}_{3}{ }^{2-}\right]=1 \times 10^{-5} \mathrm{~mol} \mathrm{~L}^{-1} ; \quad[\mathrm{SDBS}]=5 \times 10^{-4} \mathrm{~mol} \mathrm{~L}^{-1} ; \quad$ [naproxen] $=1 \times$ $10^{-6} \mathrm{~mol} \mathrm{~L}^{-1}$; [hyprochloric acid $]=60 \mathrm{mmol} \mathrm{L}^{-1}$.

\subsection{Interference studies}

The tolerable concentration ratios with respect to $5.0 \times 10^{-8} \mathrm{~mol} \mathrm{~L}^{-1}$ naproxen for interference at $5 \%$ level were examined. Thousand-fold excess $\mathrm{Mg}^{2+}, \mathrm{Na}^{+}, \mathrm{K}^{+}, \mathrm{NH}_{4}{ }^{+}$, $\mathrm{Ca}^{2+}, \mathrm{C}_{2} \mathrm{O}_{4}{ }^{2-}, \mathrm{HCO}_{3}{ }^{-}, \mathrm{H}_{2} \mathrm{PO}_{4}{ }^{-}, \mathrm{SO}_{4}{ }^{2-}, \mathrm{Zn}^{2+}$, acetate, dextrin, glucose, sucrose, starch, urea, $\mathrm{V}_{\mathrm{C}}, 100$-fold uric acid, citrate, lactate, $\mathrm{V}_{\mathrm{B} 1}, \mathrm{~V}_{\mathrm{B} 2}, \mathrm{Fe}^{2+}, 50$-fold $\mathrm{Cu}^{2+}, \mathrm{Co}^{2+}, \mathrm{Mn}^{2+}$, had almost no effect on the determination of sulfite.

\subsection{The CL mechanism studies of the present system}

The CL spectra of the present system with and without naproxen, as illustrated in Fig. 7, were monitored by the spectrofluorometer with the Xe light turned off and the emitted slit width set at $20 \mathrm{~nm}$. As well known, the cage structure of the micelle is helpful for stabilizing excited state luminophor to prevent it from quenching [13]. Hence, the CL signals of sulfite acidic system in the presence of SDBS could be observed as shown in Figs.2b and 7 (solid line). The CL spectrum of sulfite-SDBS acidic system extends from 400 to $525 \mathrm{~nm}$. Although, in Fig. 7 (dash line), the CL intensity of the naproxen-sulfite-SDBS system has a significant increase, its spectrum shows a similar range and profile to the CL spectra reported by Stauff and Jaeschke [14]. Thus, the emitter of the present CL reaction was the excited sulfur dioxide, which gave out an emission when it returned to its ground state. Since the excitation and emission wavelength of naproxen were 272 and $355 \mathrm{~nm}$, respectively, the energy transfer was not responsible for the sensitizing effect. From the fluorescence and UV-visible spectrum of the products of the CL reaction we concluded that naproxen was not oxidized and naproxen was only a sensitizer of the CL reaction because of the absence of the emission at $440 \mathrm{~nm}$ of the oxidation products of naproxen [15]. Thereafter, the mechanism for how the significant CL signal yielded was believed to be a microenvironment surfactant effect. On one hand, the predominant form of naproxen in $60 \mathrm{mmol} \mathrm{L}^{-1}$ hydrochloric acid is its molecular form due to $\mathrm{p} K_{\mathrm{a}}=4.8$. Thus, most of the naproxen molecular entered the cage structure of SDBS micelles. On the other hand, as to the phenomenon reported by Correa et al. [16], the naproxen solubility increased significantly because of the incorporation of naproxen in the microemulsion. In this way, naproxen increased the hydrophobicity of the SDBS micelle compartmentalization, which could increase the aggregation number of SDBS micelles [17]. Hence, the formation of micelles and the incorporation of naproxen furthermore stabilized the excited state of $\mathrm{SO}_{2}{ }^{*}$ generated in this CL reaction and improved the CL quantum yield about 30 times, which could be seen in Figs.2c and 7 (dash line). The CL mechanism could be interpreted as follows [18-21]:

$$
\begin{aligned}
& \mathrm{O}_{2}+4 \mathrm{HSO}_{3}{ }^{-}+4 \mathrm{H}^{+} \rightarrow 4 \mathrm{HSO}_{3}^{\bullet}+2 \mathrm{H}_{2} \mathrm{O} \\
& 2 \mathrm{HSO}_{3}{ }^{\bullet} \rightarrow \mathrm{S}_{2} \mathrm{O}_{6}{ }^{2-}+2 \mathrm{H}^{+} \\
& \mathrm{S}_{2} \mathrm{O}_{6}{ }^{2-} \rightarrow \mathrm{SO}_{4}{ }^{2-}+\mathrm{SO}_{2}^{*} \\
& \mathrm{SO}_{2}{ }^{*} \rightarrow \mathrm{SO}_{2}+h v
\end{aligned}
$$

\subsection{Sample analysis}

\subsubsection{Determination of naproxen in pharmaceutical tablets}

The proposed method was applied to the determination of naproxen in pharmaceutical preparations. The measured

\begin{tabular}{|c|c|c|c|c|c|c|c|}
\hline Sample no. & Found $\left(\mathrm{ng} \mathrm{mL} L^{-1}\right)$ & Added $\left(\mathrm{ng} \mathrm{mL} \mathrm{m}^{-1}\right)$ & Total $\left(\mathrm{ng} \mathrm{mL} \mathrm{L}^{-1}\right)$ & Recovery (\%) & R.S.D. $(n=5, \%)$ & Content $\left(\mathrm{g} \mathrm{tablet}^{-1}\right)$ & Label $\left(\mathrm{g} \mathrm{tablet}^{-1}\right)$ \\
\hline 1 & 20.26 & 10.00 & 29.83 & 98.3 & 1.72 & 0.1013 & 0.100 \\
\hline 2 & 20.68 & 20.00 & 40.75 & 103.8 & 1.53 & 0.1034 & 0.100 \\
\hline 3 & 19.49 & 30.00 & 50.15 & 100.5 & 2.61 & 0.0975 & 0.100 \\
\hline
\end{tabular}
naproxen contents are listed in Table 4.

Table 4

Results of naproxen in naproxen tablet 


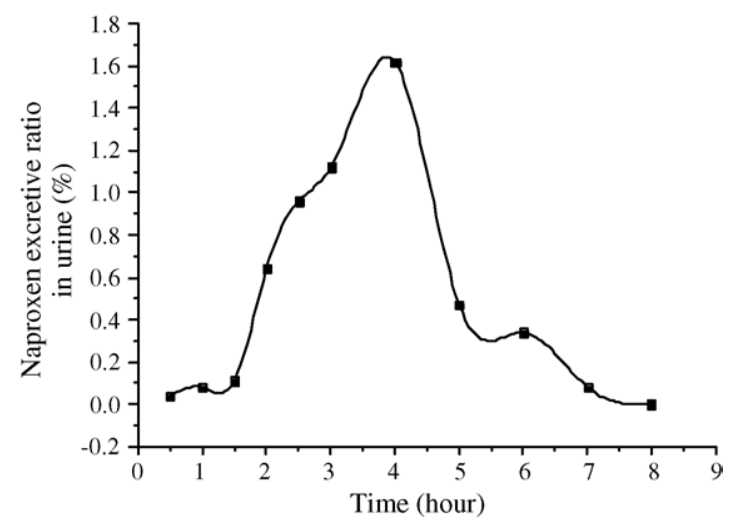

Fig. 8. The excretive profile in urine after single oral dose of naproxen.

\subsubsection{In vitro monitoring of excretive naproxen in human urine}

Two healthy male volunteers took $200 \mathrm{mg}$ naproxen tablets orally in morning with empty stomach. After that, urine samples were collected in glass beakers after $0.5,1.0,1.5,2.0,2.5,3.0$, $4.0,5.0,6.0,7.0$ and $8.0 \mathrm{~h}$, respectively. The total volume of each collected urine sample was determined and recorded. The developed sample treatment and determination procedure were immediately applied to the urine samples without any delay. The results of trial determinations are summarized in Fig. 8. It was found that excretive naproxen reached a maximum in $4.0 \mathrm{~h}$ after taking the naproxen tablets; the total naproxen excreted through urine was $\mathrm{mg}$ in a total volume of $846 \mathrm{~mL}$ in $8.0 \mathrm{~h}$ with a total excretive ratio of $5.46 \%$.

\section{Conclusion}

A flow-injection CL method for the determination of naproxen in real urine sample was developed for the first time and the naproxen excretive profile in urine was given. It was found that naproxen could efficiently enhance the CL signal of $\mathrm{SO}_{3}{ }^{2-}$-SDBS in hydrochloric acid medium. As compared with the known Ce (IV) CL method in sulfuric acid, the proposed method in the presence of SDBS micelles had a good sensitivity, selectivity, precision and wide linear range, which allowed potential application in pharmaceutical and biological sample analysis.

\section{Acknowledgements}

The authors gratefully acknowledge financial support of the National Science Fund for Distinguished Young Scholars of China (No. 20125514), National Natural Science Foundation of China (No. 20437020, 50273046), 863 Program (No. 2001AA635030) and Major Research Program of Chinese Academy of Sciences (KZCX3-SW-432).

\section{References}

[1] C. Boynton, C. Dick, F. Mayer, J. Clin. Pharmacol. 28 (1988) 512.

[2] L. Monser, F. Darghouth, J. Pharm. Biomed. Anal. 32 (2003) 1087.

[3] T. Pérez-Ruiz, C.M. Lozano, V. Tomás, J. Carpena, Fresenius J. Anal. Chem. 361 (1998) 492.

[4] P. Damiani, M. Bearzotti, M.A. Cabezón, J. Pharm. Biomed. Anal. 29 (2002) 229.

[5] M. Fillet, L. Fotsing, J. Bonnard, J. Pharm. Biomed. Anal. 18 (1998) 799.

[6] J.A. Arancibia, G.M. Escandar, Analyst 126 (2001) 917.

[7] N. Adhoum, L. Monser, M. Toumi, K. Boujlel, Anal. Chim. Acta 495 (2003) 69.

[8] J. Sádecká, M. Čakrt, A. Hercegová, J. Plolnský, J. Pharm. Biomed. Anal. 25 (2001) 881.

[9] P.C. Camiani, M.D. Borraccetti, A.C. Olivieri, Anal. Chim. Acta 471 (2002) 87

[10] A. Campiglio, Analyst 123 (1998) 1571.

[11] Y.D. Liang, J.F. Song, J. Pharm. Biomed. Anal. 38 (2005) 100.

[12] C.N. Wang, Z.H. Song, Bioorg. Med. Chem. Lett. 14 (2004) 4127.

[13] C.M. Paleos, G. Vassiloppulos, J. Nikokavouras, J. Photochem. 18 (1982) 327.

[14] J. Stauff, W.A. Jaeschke, Naturforschung B 33B (1978) 293.

[15] M. Valero, B. Esteban, J. Photochem. Photobiol. B: Biol. 76 (2004) 95.

[16] M.A. Correa, M.V. Scrapa, M.C. Franzini, A.G. Oliveira, Colloids Surf. B 43 (2005) 108.

[17] E. Pramauro, E. Pelizitti, in: S.G. Weber (Ed.), Surfactants in Analytical Chemistry, Comprehensive Analytical Chemistry, vol. XXXI, Elsevier, Amsterdam, The Netherlands, 1996, p. 46.

[18] F. Meixner, W. Jaeschke, Fresenius Z. Anal. Chem. 317 (1984) 343.

[19] K. Takeuchi, T. Ibusuki, Anal. Chim. Acta 174 (1985) 359.

[20] A.B.E. Syropoulos, G. Sarantonis, A.C. Calokerinos, Anal. Chim. Acta 239 (1990) 195.

[21] J.-M. Lin, T. Hobo, Anal. Chim. Acta 323 (1996) 69. 